\title{
Job satisfaction, workplace stress, unhealthy lifestyle choices, and productivity among Canadian nurses: an empirical study
}

Karen J. Buhr ${ }^{1}$

Lecturer in Health Administration, Penn State Harrisburg

\begin{abstract}
BACKGROUND: Nurses' occupational stress and job satisfaction can have an affect on lifestyle choices and productivity. OBJECTIVES: The objective of this study is to provide a detailed examination of the relationship between job satisfaction, job stress, unhealthy lifestyle choices, and productivity among Canadian nurses. METHODS: This study uses data from the confidential master data files of the 2005 National Survey of the Work and Health of Nurses (NSWHN). Ordinary least squares regressions and binary probit regression models were used to estimate the relationships between job satisfaction and job stress on productivity and unhealthy lifestyle choices. RESULTS: Workplace stress variables have a small effect on lifestyle choices. Job satisfaction has an effect on the probability of smoking, but not on drinking. Workplace stress and job satisfaction do not have statistically significant effects on productivity. DISCUSSION: The study found weak relationships among the work related stress variables and productivity. These findings can allow policy makers to consider efforts to reduce workplace stress which can be beneficial to productivity.
\end{abstract}

\section{Keywords}

Job satisfaction; Occupational stress; Working environment

\section{INTRODUCTION}

The major objective of this study is to provide a detailed examination of the relationships between job satisfaction, job stress, unhealthy lifestyle choices, and productivity. In particular, this research will address whether job satisfaction and work related stress among Canadian nurses prompt unhealthy lifestyle decisions, such as smoking, drinking, overeating and lack of exercise, among this occupational group. The second question this research will address is whether job satisfaction, workplace stress, and unhealthy lifestyle choices impact productivity.

This study may have numerous potentially important policy implications. Firstly, if we can understand the underlying causes, such as job stress and satisfaction, behind unhealthy decisions, we can start to work on changing these behaviors through public policy. Secondly, we will examine the relationship between productivity and unhealthy lifestyle choices. Unhealthy people are more likely to take sick days [1-4], which has a major impact on productivity and patient care in medical facilities. Finally, a better understanding of the relationships among these variables has the potential to improve our ability to retain and recruit much needed nurses in Canada.

This study will also provide important information to a number of stakeholder groups, including nurses (and nursing unions), medical facility managers, and the general Canadian public. Nurses and nursing unions would be interested in this study as a justification to seek improved working conditions from management officials, especially if we can show that stress and satisfaction are closely related to the overall health and well being of nurses. Managers in hospitals and other health care facilities would be interested in this study from a retention and recruitment standpoint. Finally, there is an increased cost to the government and taxpayers in Canada if higher levels of stress are associated with increased unhealthy choices such as drinking, smoking and lack of exercise. These ac-
Corresponding authors

Dr. Karen J. Buhr kjb44@psu.edu

\section{Disclosure}

No funding was received to prepare this article 
tions can lead to higher health care costs to society when associated with adverse health outcomes such as diabetes, lung cancer, etc. Our main contribution is to examine the relationships between job satisfaction, work place stress, unhealthy lifestyle decisions, and their overall impact on the productivity of Canadian nurses. Once we have a better understanding of these relationships, we can look at ways to improve health outcomes of nurses in Canada (better pay, fewer hours, greater staff to patient ratio, etc.).

\section{LITERATURE REVIEW}

Occupational stress can have serious consequences for nurses and for their patients. A strong relationship has been documented between workplace stress and job satisfaction [5-7]. Other studies identify the relationship between workplace stress, job satisfaction, and employment turnover [8,9], while additional studies examine the relationship between disease and health, job satisfaction, and stress [10-12].

Several studies look at some, but not all, aspects of this relationship among nurses. One study examines the relationship between job satisfaction and job stress [13] while another examines the relationship between lifestyle choices and social support [14]. A study by Halkos and Bousinakis [15] examines the effect of stress and satisfaction on productivity. A study by Anderson and Beck [16] examines the relationship between job satisfaction, job stress, and smoking. This study will extend these analyses and add to the literature by looking at the relationships between job satisfaction, job stress, and various unhealthy lifestyle choices as well as the relationships between job satisfaction, job stress, various unhealthy lifestyle choices, and productivity for a specific group of individuals.

\section{METHOD}

\section{Data description}

Data for this study come from the $2005 \mathrm{Na}$ tional Survey of the Work and Health of Nurses (NSWHN). The survey was conducted by Statistics Canada in partnership with the Canadian Institute for Health Information and Health Canada. The survey was administered to a nationally representative sample of licensed practical nurses (LPNs), registered nurses (RNs) and registered psychiatric nurses (RPNs) from across Canada. The 2005 NSWHN was designed to be representative of nurses who were registered and employed in nursing in Canada at the time of the interview. Data from the survey were weighted to permit representative estimates of each of three nursing bodies, registered nurses, licensed practical nurses and registered psychiatric nurses, at the provincial level. The survey had an $80 \%$ response rate and nearly 19,000 Canadian nurses completed the survey. The survey asked questions about their earnings, their education and their experience as well as about the conditions in which they work, the difficulties they face in doing their jobs, and their physical and mental well-being. Questions were also asked about nurses' views of work stress, role overload, respect and quality of patient care. This survey includes a wealth of information about nurses and their work.

Access to confidential data is permissible by applying for access to use restricted data files. A proposal is submitted to the Social Sciences and Humanities Research Council, and once approval is received, secure access to detailed Statistics Canada data is made available at a Research Data Center at one of several Canadian universities. The Research Data Center program is part of a national university initiative to use Statistics Canada master files with a view to strengthening social research capacity and supporting social and economic policy analysis in Canada.

\section{The outcome variables}

There are five outcome variables of interest that address the two questions being asked in this study. The first three outcome variables measure unhealthy lifestyles and are body mass index, smoking, and drinking. The final two outcome variables measure productivity and are chronic illness and absences from work.

The three measurements of unhealthy lifestyles include one continuous dependent variable self reported body mass index (BMI). This measure gives some indication of health. A higher BMI might indicate less healthy lifestyle choices of overeating and insufficient exercise. The other two dependent variables are dichotomous variables. The first of these is a variable that indicates whether the individual consumes alcohol on a regular basis or whether the individual does not consume alcohol or is a former drinker. The second of these is a variable that indicates whether the individual is a regular smoker or whether the individual is a non-smoker or is a former smoker. Both smoking and drinking are frequently viewed as being unhealthy and will be used in this study as a measure of unhealthy lifestyle choices.

The two measures of productivity include one continuous and one dichotomous variable. The continuous variable is absences 
from work and is measured in days. The second measure of productivity is the presence of a chronic health condition. In the survey, nurses were asked if they had a specific longterm condition that has lasted or is expected to last 6 months or more and that has been diagnosed by a health professional. The chronic conditions included the following: allergies, asthma, fibromyalgia, arthritis or rheumatism, back problems, high blood pressure, high cholesterol levels, migraine headaches, diabetes, heart disease, cancer, stomach or intestinal ulcers, sleep disorder (such as sleep apnea), bowel disorder (such as Crohn's disease or colitis), thyroid condition, chronic fatigue syndrome, multiple chemical sensitivities, and depression [17]. Chronic health conditions have been found to have a negative effect on worker productivity [1-3].

\section{The independent variables}

The independent variables include several dichotomous, categorical, and continuous variables that fit into demographic and work related groups. The demographic variables under consideration include one continuous variable (age), two dichotomous variables (gender and full time employment), and several categorical variables (income, marital status, education, occupational groupings, and place of employment).

Each of the independent variables is expected to have an effect on job satisfaction and workplace stress which in turn have an effect on lifestyle choices and productivity: demographic characteristics such as age, marital status and education [18-20], working situations such as job rank, work time [13,21-23]. In this sample the individuals are categorized into three groups based on their marital status: divorced, legally separated or widowed, legally married or in a common law relationship, and single. The individuals who are married are the reference group against whom those who are single or no longer married. The following educational levels are included: non-university certificate in nursing (the reference group), a registered nursing diploma, a Bachelors degree in nursing, and a higher degree. There are three nursing professions that are represented in this sample. These include the reference group of registered nurses (RNs), licensed practical nurses (LPNs), and registered psychiatric nurses (RPNs). The places of employment include hospitals (the reference group), long-term care facilities, community health facilities, and other places of employment.

Aside from the demographic variables there are numerous work stress and health variables of interest that might affect lifestyle choices and productivity [24]. Occupational roles such as workload, personal responsibility, role conflict $[25,26]$ and personal resources such as social support and rational coping $[27,28]$ are factors that we can expect may have an effect on satisfaction and stress, and therefore unhealthy choices and productivity. An excellent feature of the data is that it includes numerous measures of workplace stress. One derived variable in the data set is Role Overload. To measure role overload, nurses were asked to react to five statements, each with a five-point scale ranging from "Strongly agree" to "Strongly disagree". This variable is derived from five questions that were asked. The statements include:

- «I often have to arrive early or stay late to get my work done».

- «I often have to work through my breaks to complete my assigned workload».

- «It often seems like I have too much work for one person to do».

- «I am given enough time to do what is expected of me in my job».

- «I have too much to do, to do everything well».

The responses to these questions were rescaled from 0 to 4 (instead of 1 to 5) and then inverted so that the higher scores represented responses that reflect higher work overloads. A total Role Overload Score was then calculated by summing the scores of the five items having a possible range of 0 to 20, where a higher score indicates more role overload.

The Nursing Work Index (NWI) developed by Aiken and Patrician [29] is a set of measures developed to study the nursing practice environment. A series of fifteen questions were asked of the nurses and each question involved a four-point likard scale ranging from "Strongly agree" to "Strongly disagree". The answers were rescaled for each question from 0 to 3 (instead of 1 to 4 ) and then inverted. The following four components were derived from these questions: Work Autonomy Score, Control over Practice Score, Nurse Physician Relationship Score, and Organizational Support Score. The score for each component was calculated by summing the value of each question within that component. The score range for each component varied according to the number of questions that made up the component. Higher scores indicate a more positive nursing environment.

The next group of variables are those related to work stress. Jobs that are hypothesized to be the most stressful are "high-strain" jobs [30] such as those that place high demands on the workers, but offer them few opportunities to use skills and make decisions. To measure the seven components of work 
stress, nurses were asked to react to twelve statements, each with a five-point scale ranging from "Strongly agree" to "Strongly disagree". The twelve questions were rescaled from 0 to 4 (instead of 1 to 5) and then the rescaled questions were inverted. Scores were calculated by summing the item scores for each component. The following components are the measures of work stress that are included: Decision Latitude: Skill Discretion Score, Decision Latitude: Decision Authority Score, Psychological Demands Score, Job Insecurity Score, Physical Exertion Score, Social Support Score, and Job Strain Score. The scoring algorithm was created so that higher scores indicated greater psychological demands, less decision authority, or less skill discretion. A higher score indicates less decision latitude and greater work stress. Higher scores also indicate greater job insecurity, greater physical exertion, and less social support.

\begin{tabular}{lccc}
\hline & $\begin{array}{c}\text { Everyone } \\
\mathbf{n = 1 3 , 1 6 7}\end{array}$ & $\begin{array}{c}\text { Men } \\
\mathbf{n = 9 6 1}\end{array}$ & $\begin{array}{c}\text { Women } \\
\mathbf{n}=\mathbf{1 2 , 2 0 6}\end{array}$ \\
\hline Age & 43.65 & 42.0941 & 43.7523 \\
Male & 0.0612 & & \\
Female & 0.9388 & & \\
Married, common law & 0.7458 & 0.7506 & 0.7455 \\
Windowed, separated or divorced & 0.1208 & 0.0706 & 0.1241 \\
Single & 0.1334 & 0.1789 & 0.1304 \\
Certificate & 0.0605 & 0.0693 & 0.0599 \\
Registered nurse diploma & 0.4934 & 0.4450 & 0.4965 \\
Bachelor in nursing & 0.2105 & 0.2092 & 0.2106 \\
Other & 0.2356 & 0.2766 & 0.2330 \\
Hospital & 0.6408 & 0.6707 & 0.6389 \\
Long-term care facility & 0.1677 & 0.1373 & 0.1697 \\
Community health facility & 0.0849 & 0.0765 & 0.0854 \\
Other & 0.1066 & 0.1155 & 0.1060 \\
Full-time & 0.5914 & 0.7950 & 0.5782 \\
Regular alcohol consumption & 0.8687 & 0.9009 & 0.8666 \\
Regular smoker & 0.1710 & 0.2036 & 0.1688 \\
Absences from work (days) & 14.3287 & 13.7795 & 14.3645 \\
Self-rated general health & 2.8983 & 2.9222 & 2.8967 \\
Self-rated mental health & 2.9590 & 2.9787 & 2.9577 \\
Presence of chronic health & 0.7271 & 0.6799 & 0.7302 \\
condition & & & \\
Self reported body & 25.4393 & 26.5847 & 25.3646 \\
mass index (BMI) & & & \\
Very satisfied & 0.5123 & 0.4467 & 0.5166 \\
Somewhat satisfied & 0.3953 & 0.4534 & 0.3915 \\
Somewhat dissatisfied & 0.0777 & 0.0856 & 0.0772 \\
Very dissatisfied & 0.0147 & 0.0143 & 0.0147 \\
\hline
\end{tabular}

Table I. Summary statistics
Also included in the survey is a measure of respect and support. This measure is from Siegrist's [31] effort-reward imbalance scale. The Effort-Reward Imbalance Score was calculated by summing the values from three questions asked in the survey. The answers were rescaled for each question from 0 to 3 (instead of 1 to 4 ) and then inverted. A higher score indicates a greater level of respect and support at work.

One final measure of workplace stress is Exposure to Risk or Infectious Disease. Dr. Michael S. Kerr of the Institute for Work and Health (IWH) and the University of Western Ontario (UWO) designed the scale that measures the perceived risk of an infectious disease outbreak due to exposure in the workplace. To measure this concern, nurses were asked to react to five statements, each with a four-point scale ranging from "Strongly agree" to "Strongly disagree." The derived variable, Concern about infectious disease outbreak (score), was calculated by summing the values of the five questions. A higher score indicates a greater level of concern or perceived risk due to exposure at the workplace for the main nursing job.

There are also included in the survey two questions relating to nurses' self-rated health; one question is the self-rated health description index (rates general health) and the second question is the self-rated mental health index (rates mental health).

One final question that could relate to an individuals lifestyle choices and stress involves the person's satisfaction with their job. Nurses are asked how satisfied they are with being a nurse and they can respond with "Very satisfied", "Somewhat satisfied", "Somewhat dissatisfied", or "Very dissatisfied".

\section{The model}

For the purpose of this paper two types of regression models will be used. In the case of the models where the dependent variable is a continuous variable (BMI and Days absent from work), ordinary least squares regression will be used. In the cases where the dependent variable is a dichotomous variable (the individual is a regular drinker, the individual is a regular smoker, and the presence of a chronic illness), a binary probit model will be used.

The statistical package STATA was used for this analysis.

\section{FINDINGS}

\section{Summary statistics}

Table I presents the summary statistics for the full sample of nurses. The values for the 
dichotomous and categorical variables are given as a proportion of the sample, while the continuous variables are given in years. There were a total of 13,167 nurses that were kept in this study. Some individuals were omitted from the sample if they did not answer some of the questions, which reduces the sample being used from the total response. Nearly $94 \%$ of the sample is female and nearly $75 \%$ of the sample is married or in a common law relationship. Turning to the measures of lifestyle choices we can see that the average BMI is 25.4393 , nearly $87 \%$ of the sample drinks alcohol on a regular basis, and $17 \%$ of the sample is a regular smoker. The average number of days absent from work is 14.3287 and nearly $73 \%$ of the sample has a chronic health condition.

When the sample is separated by gender we can see that there are some differences across the two genders. Nearly $80 \%$ of men work full time while only $58 \%$ of women work full time. Men are slightly younger (42 years for men versus 43.8 years for women). Turning to lifestyle choices there is some variation across the genders. A larger proportion of the men drink ( $90 \%$ of men versus nearly $87 \%$ of women) and slightly more men smoke $(20 \%$ of men versus nearly $17 \%$ of women). $73 \%$ of women report a chronic illness while only $68 \%$ of men report the same. Finally, men and women both report being satisfied with being a nurse, but the distribution is more uneven among the women reporting being very satisfied or somewhat satisfied. $44.67 \%$ of men report being very satisfied and $45.34 \%$ report being somewhat satisfied while $51.66 \%$ of women report being very satisfied and $39.15 \%$ report being somewhat satisfied.

\section{Unhealthy lifestyle choices}

Table II presents the regression results that address the question of unhealthy choices. In each column the coefficients are reported and the robust standard error is reported in parenthesis. Significance for each variable is indicated with $* * *$ for $1 \%$, ** for $5 \%$, and $*$ for $10 \%$ level of statistical significance. Column (a) reports the ordinary least squares regression results for the independent variable of BMI. Columns (b) and (c) report the binary probit results for smoking and drinking respectively. Rather than reporting the coefficients of the probit models, the regression results for the binary probit models report the discrete change in the probability of being a smoker or drinker for a variety of dummy variables that are expected to affect this probability. Similarly this method is also used for the probability of having a chronic illness in the productivity regression. This method of reporting the coefficients is used to make the interpretation easier as compared to odds ratios that are traditionally reported in probit or logit regressions. In this case the reader can multiply the coefficient by 100 and interpret the coefficient as a percentage difference in the probability of being a smoker or drinker, as compared to the reference group for each of the dummy variable categories used in the analysis.

Looking at the work stress variables it can be seen that some of them have a small effect on the lifestyle choices. The only work stress variables that show a statistically significant effect on the probability of drinking are the nurse physician relationship score and the organizational support score, but they each have a very small effect. Several variables have a negative effect on the probability of smoking. For each of the variables that are statistically significant, it reduces the likelihood of smoking in the sample of nurses but again these effects are very small. As the work autonomy score increases BMI tends to increase as well. However, as role overload, the effort-reward imbalance score and exposure to risk increase, BMI decreases by a small amount.

Compared to a nurse who is very satisfied with being a nurse, someone who is somewhat satisfied has a higher BMI. Compared to an individual who is very satisfied with being a nurse, those who are somewhat satisfied or somewhat dissatisfied are $9.17 \%$ and $8.61 \%$ respectively, more likely to be a regular or occasional smoker. Job satisfaction has no statistically significant effect on drinking. Nurses who have higher self reported general health have lower BMIs, are less likely to smoke, and are more likely to drink. Nurses who report higher self reported mental health rankings are less likely to smoke. If a nurse is a regular drinker $\mathrm{s} /$ he is $1.3 \%$ more likely to also smoke and if a nurse is a regular smoker $\mathrm{s} /$ he is $2.58 \%$ more likely to also drink.

\section{Productivity}

Table III presents the regression results that address the question of productivity. Column (a) reports the binary probit results for the presence of a chronic health condition while column (b) reports the ordinary least squares regression results for the independent variable of days absent from work.

Nurses who have higher self reported general health are $10 \%$ less likely to have a chronic health condition and they have 7.5 fewer absences. Nurses who report higher self reported mental health rankings are $2.84 \%$ less likely to have a chronic health condition and they have 2.5 fewer absences. If a nurse is a 


\begin{tabular}{|c|c|c|c|c|c|c|}
\hline \multirow[b]{2}{*}{ Self-rated general health } & \multicolumn{2}{|c|}{ OLS BMI (a) } & \multicolumn{2}{|c|}{ Probit smoker (b) } & \multicolumn{2}{|c|}{ Probit drinker (c) } \\
\hline & $-0.9771^{* * \star}$ & $(0.0924)$ & $-0.0202^{* * *}$ & $(0.0066)$ & $0.0310^{* \star *}$ & $(0.0062)$ \\
\hline Self-rated mental health & 0.0037 & $(0.0923)$ & $-0.0236^{\star \star \star}$ & $(0.0070)$ & $-0.0188^{* \star *}$ & $(0.0066)$ \\
\hline Regular alcohol consumption & -0.2549 & $(0.2128)$ & $0.0131^{\star *}$ & $(0.0131)$ & & \\
\hline Regular smoker & $-0.9119^{* * *}$ & $(0.1549)$ & & & $0.0258^{* *}$ & $(0.0104)$ \\
\hline BMI & & & $-0.0056^{\star \star \star}$ & $(0.0018)$ & -0.0011 & $(0.0009)$ \\
\hline Presence of chronic health condition & $0.7233^{* * *}$ & $(0.1407)$ & -0.0114 & $(0.0123)$ & $0.0189 *$ & $(0.0112)$ \\
\hline Absences from work & 0.0019 & $(0.0018)$ & -0.0001 & $(0.0001)$ & -0.0002 & $(0.0001)$ \\
\hline Decision latitude: Skill Discretion Score & -0.0492 & $(0.0596)$ & $-0.0109 * \star$ & $(0.0047)$ & 0.0001 & $(0.0041)$ \\
\hline Decision latitude: Decision Authority Score & -0.0763 & $(0.0639)$ & $-0.0108^{\star \star}$ & $(0.0051)$ & -0.0052 & $(0.0043)$ \\
\hline Psychological Demands Score & 0.0747 & $(0.1095)$ & -0.0072 & $(0.0085)$ & 0.0067 & $(0.0071)$ \\
\hline Job Insecurity Score & -0.0140 & $(0.0679)$ & -0.0010 & $(0.0048)$ & -0.0004 & $(0.0044)$ \\
\hline Physical Exertion Score & 0.0426 & $(0.0599)$ & 0.0058 & $(0.0047)$ & 0.0034 & $(0.0041)$ \\
\hline Social Support Score & -0.0034 & $(0.0381)$ & 0.0016 & $(0.0026)$ & -0.0009 & $(0.0024)$ \\
\hline Job Strain Score & 0.5842 & $(0.7186)$ & 0.0429 & $(0.0549)$ & -0.0262 & $(0.0463)$ \\
\hline Role Overload (1-20 scale) & $-0.0490 * * \star$ & $(0.0180)$ & 0.00003 & $(0.0013)$ & 0.0007 & $(0.0012)$ \\
\hline Effort-Reward Imbalance Score & $-0.0726^{*}$ & $(0.0457)$ & $-0.0118^{\star \star \star}$ & $(0.0034)$ & 0.0029 & $(0.0032)$ \\
\hline Exposure to Risk (Infectious Disease) & $-0.0488^{\star \star \star}$ & $(0.0184)$ & $-0.0034^{\star \star}$ & $(0.0014)$ & -0.0009 & $(0.0012)$ \\
\hline Work Autonomy Score & $0.0753^{\star *}$ & $(0.0464)$ & 0.0023 & $(0.0035)$ & 0.0032 & $(0.0031)$ \\
\hline Control over Practice Score & -0.0266 & $(0.0389)$ & 0.0048 & $(0.0030)$ & 0.0028 & $(0.0026)$ \\
\hline Nurse Physician Relationship Score & 0.0658 & $(0.0521)$ & 0.0046 & $(0.0040)$ & $0.0065^{\star}$ & $(0.0036)$ \\
\hline Organizational Support Score & -0.0329 & $(0.0522)$ & $-0.0073^{\star}$ & $(0.0039)$ & $-0.0063^{*}$ & $(0.0035)$ \\
\hline Somewhat satisfied & $0.6858^{*}$ & $(0.4807)$ & $0.0917^{\star \star}$ & $(0.0409)$ & 0.0206 & $(0.0375)$ \\
\hline Somewhat dissatisfied & 0.2552 & $(0.4754)$ & $0.0861^{* *}$ & $(0.0442)$ & 0.0397 & $(0.0356)$ \\
\hline Very dissatisfied & 0.1964 & $(0.5142)$ & 0.0797 & $(0.0555)$ & 0.0399 & $(0.0317)$ \\
\hline Age & $0.0365^{\star \star \star}$ & $(0.0068)$ & $-0.0012^{\star \star}$ & $(0.0005)$ & $-0.0017^{\star \star \star}$ & $(0.0005)$ \\
\hline Income groups & $-0.0926^{\star \star}$ & $(0.0475)$ & $-0.0102^{\star \star \star}$ & $(0.0032)$ & $0.0191^{\star \star \star}$ & $(0.0029)$ \\
\hline Male & $1.3927^{\star \star \star}$ & $(0.2182)$ & 0.0305 & $(0.0216)$ & 0.0244 & $(0.0157)$ \\
\hline Windowed, separated or divorced & $-0.4278^{* *}$ & $(0.1991)$ & $0.0643^{* * *}$ & $(0.0179)$ & $0.0454^{\star \star \star}$ & $(0.0111)$ \\
\hline Single & 0.2198 & $(0.2453)$ & $0.0436^{\star \star \star}$ & $(0.0173)$ & -0.0043 & $(0.0148)$ \\
\hline Long-term care facility & -0.1570 & $(0.1649)$ & $0.0189 *$ & $(0.0128)$ & $-0.0298^{* * \star}$ & $(0.0121)$ \\
\hline Community health facility & -0.0211 & $(0.2579)$ & 0.0094 & $(0.0179)$ & $0.0233^{\star}$ & $(0.0139)$ \\
\hline Other & $-0.2786^{*}$ & $(0.1854)$ & 0.0174 & $(0.0169)$ & $0.0239 *$ & $(0.0126)$ \\
\hline LPN & $0.5812^{\star *}$ & $(0.2624)$ & $0.1099 * \star \star$ & $(0.0223)$ & -0.0069 & $(0.0186)$ \\
\hline RPN & $0.4429^{\star \star}$ & $(0.2625)$ & $0.0996^{\star \star \star}$ & $(0.0265)$ & 0.0158 & $(0.0178)$ \\
\hline Part-time & $-0.4920 * \star \star$ & $(0.1387)$ & $-0.0266^{\star \star}$ & $(0.0103)$ & 0.0037 & $(0.0093$ \\
\hline Registered nurse diploma & 0.3641 & $(0.3017)$ & $0.0634^{\star \star}$ & $(0.0248)$ & 0.0014 & $(0.0218)$ \\
\hline Bachelor in nursing & $-0.4293^{*}$ & $(0.3206)$ & -0.0194 & $(0.0255)$ & -0.0199 & $(0.0250)$ \\
\hline Other & 0.0172 & $(0.2444)$ & $0.0373^{\star}$ & $(0.0201)$ & -0.0092 & $(0.0167)$ \\
\hline N & \multicolumn{2}{|c|}{13167} & \multicolumn{2}{|c|}{13167} & \multicolumn{2}{|c|}{13167} \\
\hline R2 & \multicolumn{2}{|c|}{0.0917} & \multicolumn{2}{|c|}{0.0660} & \multicolumn{2}{|c|}{0.0538} \\
\hline
\end{tabular}

Table II. OLS Regression results (robust standard errors in parenthesis). Significance indicated by ** for 1\%, ** for $5 \%$ and * for $10 \%$ (a) Ordinary Least Squares regression where the dependant variable is BMI

(b) Probit Regression. Dependent variable is $Y_{i}=1$ if the individual is currently a regular smoker and $Y_{i}=0$ otherwise

(c) Probit Regression. Dependent variable is $Y_{i}^{i}=1$ if the individual is currently a regular drinker and $Y_{i}=0$ otherwise

regular drinker s/he has 2.53 fewer absences. Nurses who have a chronic health problem have 4.74 more absences.

In general, the work stress variables do not have a statistically significant effect on productivity and job satisfaction does not have a statistically significant effect on the productivity measures being used with the exception of nurses who are somewhat unsatisfied with being a nurse. Compared to a nurse who is very satisfied, nurses who are somewhat unsatisfied have 11 fewer absences from work. 


\begin{tabular}{|c|c|c|c|c|}
\hline \multirow[b]{2}{*}{ Self-rated general health } & \multicolumn{2}{|c|}{ Probit chronic illness (a) } & \multicolumn{2}{|c|}{ OLS sick days (b) } \\
\hline & $-0.1016^{\star \star \star}$ & $(0.0093)$ & $-7.5399 * * *$ & $(0.8991)$ \\
\hline Self-rated mental health & $-0.0284^{* * *}$ & $(0.0089)$ & $-2.5337^{* \star \star}$ & $(1.0376)$ \\
\hline Regular smoker & -0.0219 & $(0.0173)$ & -1.2229 & $(1.3900)$ \\
\hline Regular alcohol consumption & 0.0282 & $(0.0195)$ & $-2.5904^{\star}$ & $(1.8754)$ \\
\hline BMI & $0.0071^{\star \star \star}$ & $(0.0015)$ & 0.1449 & $(0.1350)$ \\
\hline Presence of chronic health condition & & & $4.7395^{\star \star \star}$ & $(0.8874)$ \\
\hline Decision latitude: skill discretion score & -0.0043 & $(0.0063)$ & 0.1806 & $(0.5556)$ \\
\hline Decision latitude: decision authority score & -0.0034 & $(0.0071)$ & -0.1924 & $(0.5868)$ \\
\hline Psychological demands score & 0.0030 & $(0.0128)$ & 0.7058 & $(0.9963)$ \\
\hline Job insecurity score & 0.0004 & $(0.0062)$ & -0.5742 & (0.5319) \\
\hline Physical exertion score & 0.0091 & $(0.0057)$ & $0.8503^{* *}$ & $(0.4616)$ \\
\hline Social support score & $0.0089^{\star *}$ & $(0.0035)$ & -0.4057 & $(0.3512)$ \\
\hline Job strain score & 0.0662 & $(0.0865)$ & -3.3151 & $(6.4874)$ \\
\hline Role overload (1-20 scale) & 0.0041 & $(0.0017)$ & 0.1108 & $(0.1283)$ \\
\hline Effort-reward imbalance score & $-0.0098^{* *}$ & $(0.0045)$ & $-1.6289^{* \star *}$ & (0.4315) \\
\hline Exposure to risk (infectious disease) & 0.0019 & $(0.0018)$ & -0.1487 & $(0.1467)$ \\
\hline Work autonomy score & 0.0041 & $(0.0045)$ & -0.3286 & $(0.3704)$ \\
\hline Control over practice score & -0.0030 & $(0.0039)$ & -0.2463 & $(0.3260)$ \\
\hline Nurse physician relationship score & -0.0006 & $(0.0052)$ & 0.3983 & (0.4523) \\
\hline Organizational support score & 0.0053 & $(0.0052)$ & 0.2919 & $(0.4470)$ \\
\hline Somewhat satisfied & 0.0559 & $(0.0589)$ & -8.9017 & (8.8232) \\
\hline Somewhat dissatisfied & 0.0552 & $(0.0569)$ & $-11.4405^{\star}$ & (8.8922) \\
\hline Very dissatisfied & 0.0768 & $(0.0514)$ & -9.6174 & $(9.3020)$ \\
\hline Age & $0.0070^{\star * \star}$ & $(0.0007)$ & 0.0269 & $(0.0537)$ \\
\hline Income groups & -0.0023 & $(0.0041)$ & $-1.4094^{* \star *}$ & $(0.3727)$ \\
\hline Male & $-0.0455^{\star}$ & $(0.0275)$ & -2.0097 & (2.0136) \\
\hline Windowed, separated or divorced & -0.0199 & $(0.0227)$ & 0.1222 & $(1.8229)$ \\
\hline Single & 0.0295 & $(0.0195)$ & -0.0477 & $(1.8279)$ \\
\hline Long-term care facility & -0.0043 & $(0.0163)$ & $-2.4286^{\star \star}$ & $(1.3431)$ \\
\hline Community health facility & 0.0014 & $(0.0215)$ & -1.7300 & $(1.8376)$ \\
\hline Other & 0.0129 & $(0.0194)$ & $-2.5554^{\star *}$ & $(1.4287)$ \\
\hline LPN & -0.0026 & $(0.0238)$ & 0.1311 & (2.3439) \\
\hline RPN & -0.0283 & $(0.0273)$ & 2.8384 & $(2.2560)$ \\
\hline Part-time & -0.0012 & $(0.0132)$ & $-2.3519^{* *}$ & $(1.1659)$ \\
\hline Registered nurse diploma & 0.0139 & $(0.0302)$ & -1.5505 & (3.5413) \\
\hline Bachelor in nursing & 0.0027 & $(0.0319)$ & -2.6969 & (3.7161) \\
\hline Other & $0.0424^{\star}$ & $(0.0229)$ & -1.5536 & (2.7961) \\
\hline $\mathrm{N}$ & \multicolumn{2}{|c|}{13167} & \multicolumn{2}{|c|}{13167} \\
\hline R2 & \multicolumn{2}{|c|}{0.1139} & \multicolumn{2}{|c|}{0.0828} \\
\hline
\end{tabular}

Table III. Productivity regressions (robust standard errors in parenthesis). Significance indicated by *** for $1 \%$, ** for $5 \%$ and * for $10 \%$

(a) Probit Regression. Dependent variable is $Y_{i}=1$ if the individual has a chronic illness and $Y_{i}=0$ otherwise

(b) Ordinary Least Squares regression where the dependant variable is sick days missed from work

Nurses working in long term care facilities, community health facilities and other work settings have fewer absences than those who work in hospitals. This is not statistically significant for those working in community care, but is for the other two. For each nurses working in those setting have around 2.5 days fewer absences.

\section{DISCUSSION}

In general, job satisfaction and workplace stress do not have many significant effects on lifestyle choices and productivity for this sample of Canadian nurses. This can be viewed as reassuring. There do not seem to be any strong correlations between unhealthy behaviours, such as drinking or 
smoking, and workplace stress or job satisfaction. When there is a statistically significant effect it is very small. Similarly, work place stress does not appear to have a signif- icant effect on productivity for this sample. The one area where there is a relationship is within the lifestyle choices and health variables.

\section{REFERENCES}

1. Davis K, Collins SR, Doty MM, et al. Health and productivity among US workers. The Commonwealth Fund Issue Brief, 2005

2. Goetzel RZ, Long SR, Ozminkowski RJ, et al. Health, absence, disability, and presenteeism cost estimates of certain physical and mental health conditions affecting US employers. J Occup Environ Med 2004; 48: 398-412; http:// dx.doi.org/10.1097/01.jom.0000121151.40413.bd

3. Collins JJ, Baase CM, Sharda CE, et al. The assessment of chronic health conditions on work performance, absence, and total economic impact for employers. J Occup Environ Med 2005; 47: 547-57; http://dx.doi.org/10.1097/01. jom.0000166864.58664.29

4. Robroek SJW, van den Berg TIJ, Plat JF, et al. The role of obesity and lifestyle behaviours in a productive workforce. J Occup Environ Med 2011; 68: 134-9; http://dx.doi.org/10.1136/oem.2010.055962

5. Blegen MA. Nurses' job satisfaction: a meta-analysis of related variables. Nursing Research 1993; 42: 36-41

6. Ernst ME, Franco M, Messmer PR, et al. Nurses' job satisfaction, stress, and recognition in a pediatric setting. Pediatric Nursing 2004; 30: 219-27

7. Judkins S, Rind R. Hardiness, job satisfaction, and stress among home health nurses. Home Health Care Management \& Practice 2005; 17: 113-8; http://dx.doi.org/10.1177/1084822304270020

8. Jamal M, Baba V. Job stress and burnout among Canadian managers and nurses: an empirical evaluation. Can $J$ Public Health 2000; 91: 454-8

9. Shader K, Broome ME, Broome CD, et al. Factors influencing satisfaction and anticipated turnover for nurses in an academic medical center. J Nurs Adm 2001; 31: 210-6; http://dx.doi.org/10.1097/00005110-200104000-00010

10. Bejean S, Sultan-Taieb H. Modeling the economic burden of diseases imputable to stress at work. Eur J Health Econ 2005; 50, 16-23; http://dx.doi.org/10.1007/s10198-004-0251-4

11. Cimete G, Gencalp NS, Keskin G. Quality of life and job satisfaction of nurses. Journal of Nursing Care Quarterly 2003; 18: 151-8; http://dx.doi.org/10.1097/00001786-200304000-00009

12. Faragher EB, Cass M, Cooper LC. The relationship between job satisfaction and health: a meta-analysis. Occup Environ Med 2005; 62: 105-12; http://dx.doi.org/10.1136/oem.2002.006734

13. Sveinsdóttir H, Biering P, Ramel A. Occupational stress, job satisfaction and working environment among Icelandic nurses: a cross-sectional questionnaire survey. Int J Nurs Stud 2006; 43: 875-89; http://dx.doi.org/10.1016/j. ijnurstu.2005.11.002

14. Callaghan P. Social support and locus of control as correlates if UK nurses' health-related behaviours. $J$ Adv Nurs 1998; 28: 1127-33; http://dx.doi.org/10.1046/j.1365-2648.1998.00811.x

15. Halkos G, Bousinakis D. The effect of stress and satisfaction on productivity. International Journal of Productivity 2010; 59: 415-31

16. Anderson LL, Beck K. The smoking behaviour of military nurses: the relationship to job stress, job satisfaction, and social support. J Adv Nurs 1990; 15: 843-9; http://dx.doi.org/10.1111/j.1365-2648.1990.tb01916.x

17. Statistics Canada. National Survey of the Work and Health of Nurses Microdata User Guide, 2009

18. Lambert VA, Lambert CE, Ito M. Workplace stressors, ways of coping and demographic characteristics as predictors of physical and mental health of Japanese hospital nurses. Int J Nurs Stud 2004; 41: 85-97; http://dx.doi. org/10.1016/S0020-7489(03)00080-4

19. Lu H, While AE, Barriball KL. Job satisfaction and its related factors: a questionnaire survey of hospital nurses in Mainland China. Int J Nurs Stud 2007; 44: 74-88; http://dx.doi.org/10.1016/j.ijnurstu.2006.07.007

20. Lee I, Wang HH. Perceived occupational stress and related factors in public health nurses. J Nurs Res 2002; 10 : 253-60; http://dx.doi.org/10.1097/01.JNR.0000347606.91295.76 
21. Needham I, Abderhalden C, Halfens RJ, et al. Non-somatic effects of patient aggression on nurses: a systematic review. J Adv Nurs 2005; 49: 83-96; http://dx.doi.org/10.1111/j.1365-2648.2004.03286.x

22. Inoue M, Tsukano K, Muraoka M, et al. Psychological impact of verbal abuse and violence by patients on nurses working in psychiatric departments. Psychiatry and Clinical Neurosciences 2006; 60: 29-36; http://dx.doi. org/10.1111/j.1440-1819.2006.01457.x

23. De Jonge J, Bosma H, Peter R, et al. Job strain, effort-reward imbalance and employee well-being: a large-scale crosssectional study. Social Science \& Medicine 2000; 50: 1317-27; http://dx.doi.org/10.1016/S0277-9536(99)00388-3

24. Wu H, Chi TS, Chen L, et al. Occupational stress among hospital nurses: cross-sectional survey. J Adv Nurs 2010; 66: 627-34; http://dx.doi.org/10.1111/j.1365-2648.2009.05203.x

25. Santos SR, Carroll CA, Cox KS, et al. Baby boomer nurses bearing the burden of care: a four-site study of stress, strain, and coping for inpatient registered nurses. J Nurs Adm 2003; 33: 243-50; http://dx.doi.org/10.1097/00005110200304000-00010

26. Hsu HC, Kung YW, Huang HC, et al. Work stress among nursing home care attendants in Taiwan: a questionnaire survey. Int J Nurs Stud 2007; 44: 736-46; http://dx.doi.org/10.1016/j.ijnurstu.2005.12.006

27. Pisarski A, Bohle P, Callan VJ. Effects of coping strategies, social support and work-nonwork conflict on shift workers' health. Scand J Work Environ Health 1998; 24: 141-5

28. Lambert VA, Lambert CE, Ito M. Workplace stressors, ways of coping and demographic characteristics as predictors of physical and mental health of Japanese hospital nurses. Int J Nurs Stud 2004; 41: 85-97; http://dx.doi. org/10.1016/S0020-7489(03)00080-4

29. Aiken LH, Patrician PA. Measuring organizational traits of hospitals: The Revised Nursing Work Index. Nursing Research 2000; 49: 146-53: http://dx.doi.org/10.1097/00006199-200005000-00006

30. Karasek RA. Job demands, job decision latitude, and mental strain: Implications for job redesign. Administrative Science Quarterly 1979; 24: 285-308; http://dx.doi.org/10.2307/2392498

31. Siegrist J. Adverse health effects of high effort-low reward conditions at work. J Occup Health Psychol 1996; 1: 27-43; http://dx.doi.org/10.1037/1076-8998.1.1.27 